\title{
Enzyme Cascade for Catalyzing Sucrose Oxidation in a Biofuel Cell
}

\section{Supplemental Material}

\author{
Authors: David P. Hickey, ${ }^{a}$ Fabien Giroud, ${ }^{b}$ David W. Schmidtke, ${ }^{\text {,d }}$ Daniel T. Glatzhofer, ${ }^{\text {a }}$ \\ Shelley D. Minteer*, \\ ${ }^{a}$ Department of Chemistry and Biochemistry, University of Oklahoma, Norman, Oklahoma 73019, USA \\ ${ }^{b}$ Department of Chemistry, University of Utah, Salt Lake City, Utah 84112, USA \\ ${ }^{c}$ University of Oklahoma Bioengineering Center, Materials Engineering, University of Oklahoma, Norman, \\ Oklahoma 73019, USA \\ ${ }^{d}$ School of Chemical, Biological, Materials Engineering, and Carbon Nanotube Technology Center, University of \\ Oklahoma, Norman, Oklahoma 73019, USA \\ *email: minteer@chem.utah.edu
}

\section{Amperometric determination of Inv/FDH and Inv/GOx film kinetics in sucrose:}

Inv/GOx electrode film kinetics were characterized by constant potential amperometry. Films were allowed to reach steady state at a potential that is $+0.05 \mathrm{~V}$ (vs. SCE) above the peak oxidation potential $\left(E_{p i a}\right)$ at $25^{\circ} \mathrm{C}$. The solutions were continuously stirred at $400 \mathrm{rpm}$. The charging current was allowed to dissipate for $1000 \mathrm{~s}$, and a single sucrose injection was made and allowed to reach steady state. This experiment was repeated for various sucrose concentrations shown in Figure S1. Inv/FDH electrode films were tested similarly with the exception that sequential sucrose injections were measured for a single electrode film. This was possible because of the lack of equilibration time required for mutarotation. The results are shown in Figure S1. The sucrose injection times are marked for clarity. 

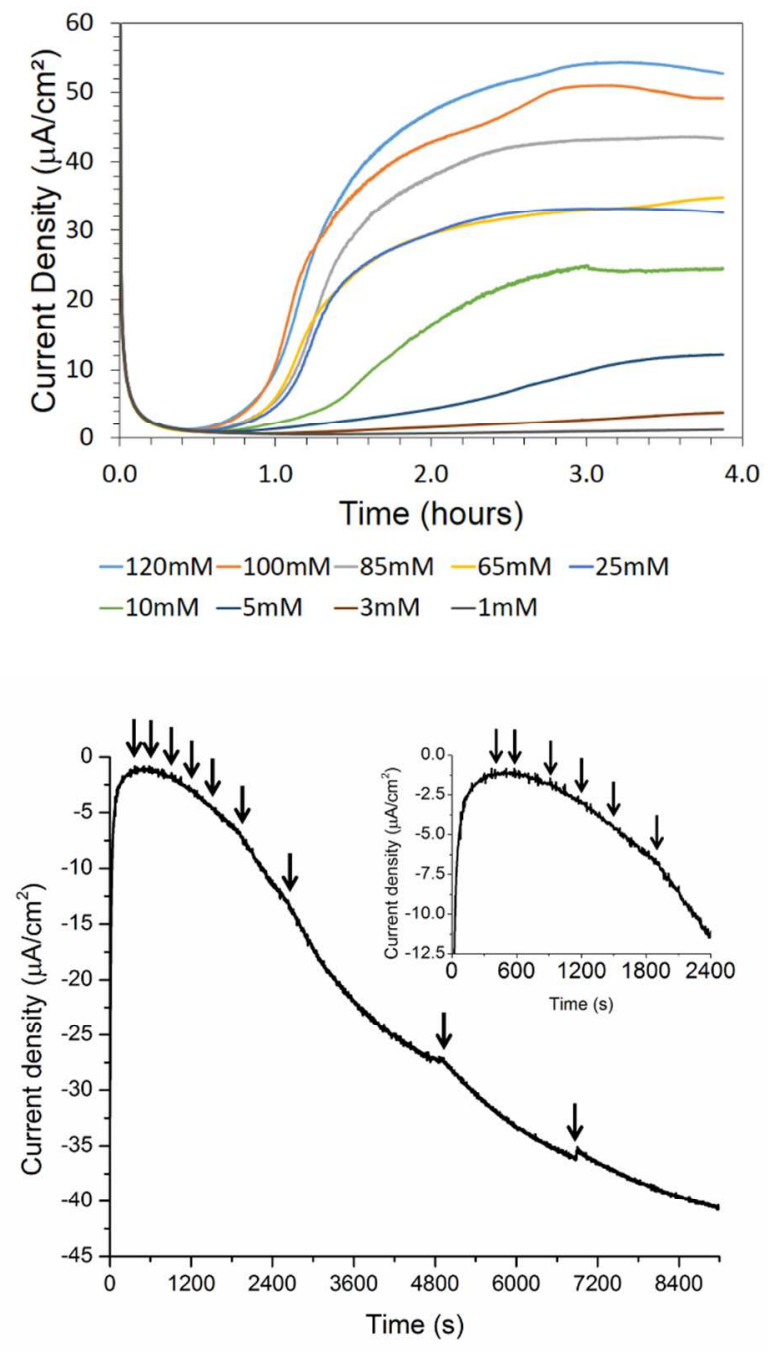

Figure S1. Current versus time plots of the amperometric response of Inv/GOx films to several different concentrations of sucrose. (top) Representative plot of Inv/FDH electrode film response to sequential sucrose injections; arrows indicate the points of sucrose injection. (bottom) Both experiments were performed in $50 \mathrm{mM}$ citrate buffer, $\mathrm{pH} 5.5$ at $25^{\circ} \mathrm{C}$. Arrows indicate the points of sucrose injection. 


\section{Mediator-less control experiments:}

Control experiments were performed by substituting the ferrocene redox polymer to a non-redox polymer. In this case, octyl-modified linear polyethylenimine $\left(\mathrm{C}_{8}\right.$-LPEI) was used as the polymer matrix for enzyme immobilization. Figure $\mathbf{S 2}$ shows the need for use of a redox mediator to help shuttle electrons from the enzymes to the electrode surface. The current density obtained in the presence of the three enzymes cascade without a redox mediator is attributed to the direct electron transfer of the FDH from its active site (pyroloquinoliquinone, PQQ) throught the heme c. [J. Tkac et al. Analytica Chimica Acta 439 (2001) 39-46]

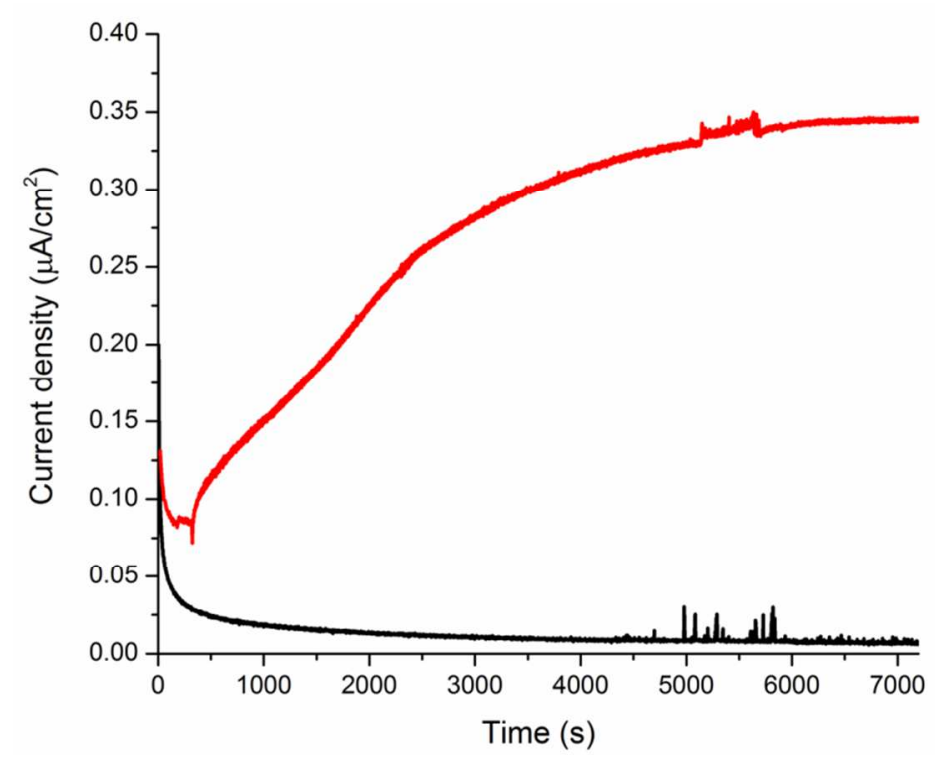

Figure S2. Amperometric responses recorded at $+0.05 \mathrm{~V}$ (vs. SCE) above $E_{\text {pia }}$ of $\mathrm{C}_{8}$-LPEI-modified electrodes without enzymes (black) and with the Inv/FDH/GOx enzymes cascade (red) at $25^{\circ} \mathrm{C}$ in $50 \mathrm{mM}$ citrate buffer $\mathrm{pH} 5.5$ with the addition of $100 \mathrm{mM}$ sucrose at $\mathrm{t}=400 \mathrm{~s}$. 


\section{Activity assay of immobilized invertase in hydrogel:}

Invertase assay: Invertase was immobilized at the bottom of a glass vial using C8-LPEI. Solutions were prepared from C8-LPEI $(60 \mu \mathrm{L}, 12 \mathrm{mg} / \mathrm{mL})$, invertase $(25.74 \mu \mathrm{L}$ total), and EGDGE (3.22 $\mu \mathrm{L}, 2 \mu \mathrm{L}$ EGDGE per $45 \mu \mathrm{L}$ H2O). invertase solutions consisted of invertase $(8.58 \mu \mathrm{L}, 20 \mathrm{mg} / \mathrm{mL})$ diluted in $17.16 \mu \mathrm{L} 18 \mathrm{M} \Omega \mathrm{cm}$ de-ionized H2O. The solution was mixed together and vortexed for 1 minute until the solution was homogeneous; then $25 \mu \mathrm{L}$ of this mixture was drop-casted directly at the bottom of the vial. A total of 10 films in 10 separate vials were allowed to cure open to the atmosphere overnight at $25{ }^{\circ} \mathrm{C}$. Each film was used to test a single sucrose concentration in presence of invertase. Sucrose concentrations were $0,1,2,3,4,5$, $10,20,50$ and $100 \mathrm{mM}$.

$450 \mu \mathrm{L}$ of each sucrose solutions were carefully injected into the vial and the solutions were incubated exactly $15 \mathrm{~min}$ at $25{ }^{\circ} \mathrm{C}$. After incubation, $5 \mu \mathrm{L}$ of the solutions were taken from the vials and added to $1495 \mu \mathrm{L}$ of alkali-PAHBAH reagent, and the mixture was heated to $75{ }^{\circ} \mathrm{C}$ for $10 \mathrm{~min}$. After the reaction of the reducing sugars was complete, $125 \mu \mathrm{L}$ of the solutions were taken and further diluted into a cuvette with $1 \mathrm{~cm}$ length pathway with $1375 \mu \mathrm{L}$ citrate buffer. Finally, the absorbance was read at $\lambda=410 \mathrm{~nm}$. The absorbance was reported compared to the starting concentration of sucrose used during the assay. (Figure S3)

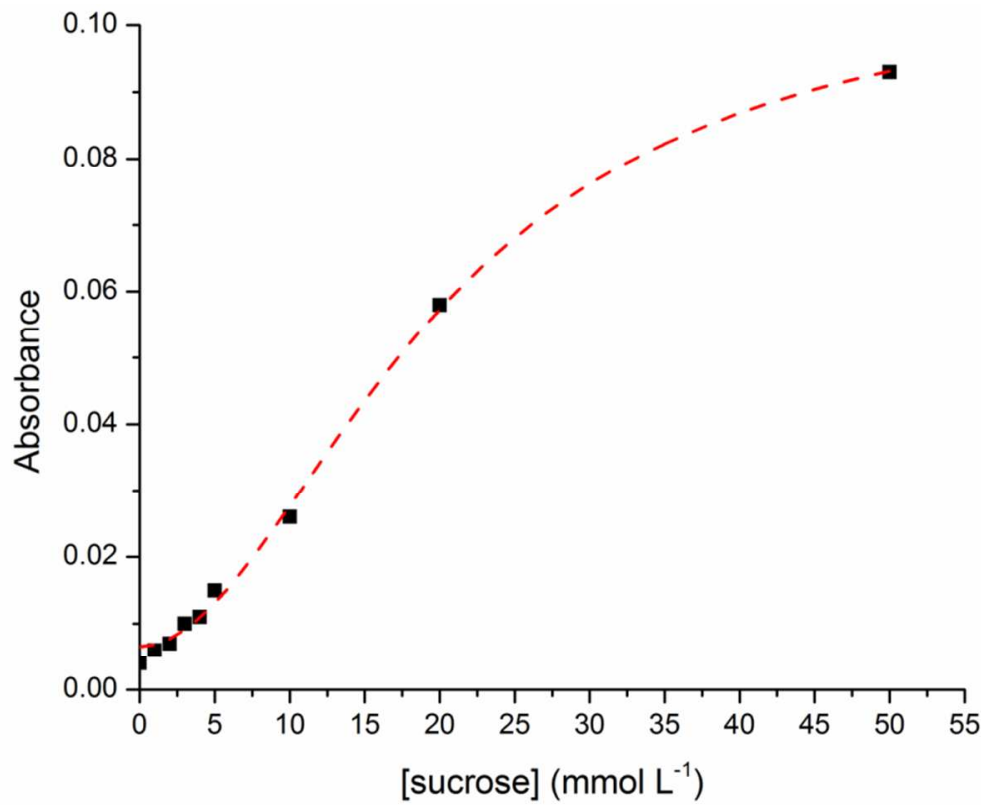

Figure S3: Absorbance change at $\lambda=410 \mathrm{~nm}$ of a PAHBAH solution in presence of different concentration of sucrose first incubated for $15 \mathrm{~min}$ at $25{ }^{\circ} \mathrm{C}$ in presence of immobilized invertase in a $\mathrm{C}_{8}$-LPEI hydrogel film. 


\section{Stability study of single oxidoreductases:}

Stability of fructose dehydrogenase (FDH) and glucose oxidase (GOx) was determined by daily chronoamperometric tests. Electrodes were poised at $+0.05 \mathrm{~V}$ (vs. SCE) above the peak oxidation potential $\left(E_{\text {pia }}\right)$ and the substrates were added at a concentration of $100 \mathrm{mM}$ at $\mathrm{t}=400$ s. When not used, the electrodes were kept in buffer and at $4{ }^{\circ} \mathrm{C}$.
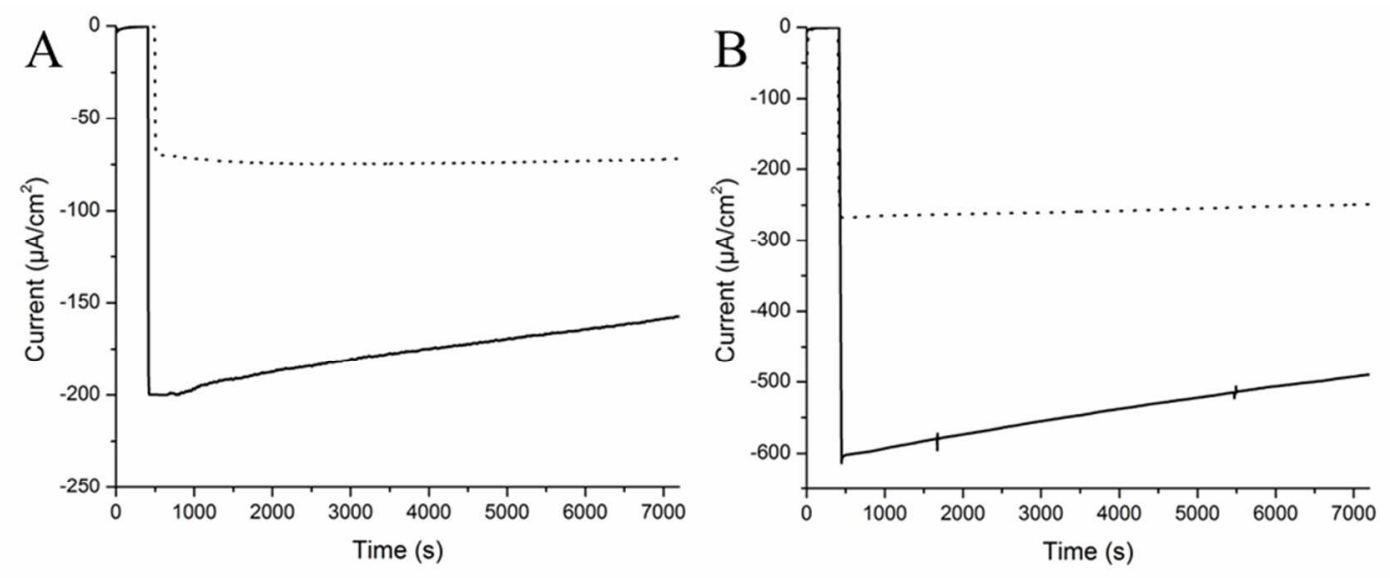

Figure S4. (A) Amperometric responses recorded at FDH-modified electrodes in $100 \mathrm{mM}$ fructose solution, day 1 (solid) and day 6 (dot). (B) Amperometric responses recorded at GOx-modified electrodes in $100 \mathrm{mM}$ glucose solution, day 1 (solid) and day 6 (dot). 